\title{
Daniel in the lion's den: attachment to a purchaser
}

\author{
Richard Fry
}

\begin{abstract}
This aficle describes a partitime aftochment to the public heath depcriment of a purchosing outhortly. duting my senior registror training in child poychiotity. This London purchaing authorlty wos responetble for resecuching needs and prortiles, plonning services and drawing up and odministering contracts for an area proviousty adminietered by severd separate hectth outhortibes. In comying out these takks if worked in close colloboration with its loced public hectth depatiment, but wos not directly linked to a Family Hectin Services Authortly.
\end{abstract}

\section{Context}

Seeing a purchaser at work from a public health department presented an interesting perspective, since public health has been grappling with its own position in the internal market (Harris \& Shapiro, 1994). This was illustrated by a debate during my attachment about the current role of the Medical Director of Public Health's report. Previously this annual report highlighted the current state of the health of the local community, advances made during the past year, future targets and ways of achieving them. Thus it affirmed the department as an advocate for the public's health. In the new environment the role of the public health department has changed: it now advises the management tier in creating 'health strategy'. In doing so the public health department increased its power, but decreased its independence and advocacy role, and became more pragmatic about what can be asked of providers. Negotiation therefore shifted from a public health/service (now providers) axis to a tripartite arrangement where public health negotiated with contracts managers who in turn negotiated with providers. It also changed routes for the flow of information from the community and providers back to those planning service provision: were the providers to interact with contracts managers, or public health in conveying their views?
There was a striking need to tap any potential source of expertise in a world where deadlines play a central role. I became involved in drafting the local strategy for purchasing child mental health services. Pre-existing documents and guidelines on current topics of interest were eagerly sought and, on discovery, celebrated. This was at least as much to do with information overload as time. Departments were in danger of being submerged in vast amounts of paper so it was necessary to bin about $50 \%$ of departmental circulars and documents just to get by. Moving between a clinical unit without resources for a basic word-processor and here where a personal computer stood on every desk it was apparent that while clinicians' raw material is patients, that of managers is information. Despite this apparent richness of resources only $1 \%$ of the annual central government allocated budget was apportioned to running costs of the purchasing organisation. In attempting to see the application of this information in practice I shadowed a contracts manager for a day. The manager had an admirable ability to think on his feet, negotiate in tough and sensitive areas, and displayed a great stamina through very long meetings. The day was ten hours long. and he then took home a large pile of material to work on overnight. This was routine for a number of people in the organisation. Many also attended at least one or two evening meetings per week.

\section{Aspects of the experience related to child poychiatry}

There was, of course, much interest in outcome measures in child psychiatry. The publication of the Association of Child Psychologists and Psychiatrists proposed core data set, including a suggested framework for outcome measures was a welcome event (Berger et al, 1993). There was 
also a relative lack of understanding about how child psychiatry might differ from its adult sibling. In particular, writing strategies and thinking about contracts helped to focus attention on the particular difficulties of commissioning multidisciplinary services for children. I supplied discussion papers on the multidisciplinary team (Kraemer, 1993) and evidence concerning the effectiveness of child psychological and psychiatric treatment (Kurtz, 1992), as well as repeatedly raising the subject of joint purchasing. but these are complex areas to consider and explain. Our professional body (of child mental health workers) needs to have a clearly developed view about this, and the recent document on purchasing from the Child and Adolescent Psychiatry Section of the College is helpful (Royal College of Psychiatrists, 1994). However, it is evident that some purchasers' knowledge of child and adolescent mental health services may be quite scanty (Vanstraelen \& Cottrell, 1994) and it is not clear whether the supply of all this information had any discernible effects.

It was difficult to explain who to negotiate contracts with in child psychiatry when it is unclear who exactly the customer might be. The co-ordinating and conflicting roles of the various referral agencies in our field are not straightforward. In this respect the ACPP outcomes proposals mentioned above are helpful. There was also a lively interest in "needs based purchasing plans for child mental health", as outlined by Light \& Bailey (1993). Indeed much discussion around the issue of "needs based assessment" took place, involving a debate about the definition of "need". One view defines it as "the ability to benefit from health care" (Stevens \& Gabbay, 1991), another as "those with recognised medical/psychological problems that are not self-correcting" (Light \& Bailey, 1993). The former is a pragmatic approach, but one which individually oriented cliniclans may have some difficulty in coming to terms with. Despite the problems and possible flaws in Light \& Bailey's approach (Cottrell, 1993), and the debate around needs assessment in general (Slade, 1994) such concepts are obviously highly attractive to managers in offering apparent solutions to budgeting and contracting problems and were hot issues.

\section{Comment}

I am now far more inclined towards cock-up than conspiracy theory. 'Managers' are as disparate a collection of occupations as a 'hospital' or 'provider unit' (managers/ purchasers) and do not have an easy time of it. The particular perspective of one department may not be shared by another in the same organisation. The amount of information to be dealt with is vast. Helpful brief documents (on easily recognisable coloured paper) summarising the situation on any topic of interest to them from your viewpoint will be welcomed, the more clearly referenced the better. Pro-activity is best. If you can manage to meet anybody in the organisation regularty, seize the opportunity. but this may prove difficult: time pressures meant I lunched on a sandwich with my colleague who introduced me to the idea of the attachment twice in six months. The culture is different to clinical medicine, with rapid turnover of personnel, and those outside the organisation can be unaware of relevant hierarchies, rapidly changing priorities, and who best to negotlate with; this may only become clear through dialogue. One view expressed to me was that child psychiatry may be vulnerable if we do not attempt to balance a view that sees us as a low mortality. low prestige sector of the service with a complicating medical/non-medical split. Managers are, for good or ill, extremely interested in costed treatment packages. I had to abandon initial ideas that as an external observer I was well placed to 'understand' problems in the system so, as some might say. I have moved to a secondorder position. (Foerster, 1981). This could mean that I am not the only one who was confused and the only way forward is to construct a new version of the reality of purchasing, together.

\section{References}

BERGER, M., HIL, P., SEN, E., THOMPSON, M. \& VERDUYN, C. (1993) A Proposed Core Data Set for Child and Adolescent Psychology and Psychiatry Services. London: Assoctation of Child Psychologists and Psychlatrists.

Cormresu. D. (1993) Pound foolish: a review Psychiatric Bulletton, 17, 480.

FOERSTER, H. von (1981) Obseruing Systems. Seaside. CA: Intersystems Publications.

HARRus. A. \& SHAPIRO. J. (1994) Purchasers, professionals and public health. British Medical Joumal, 308, 426427. 
KRAEMISR, S. (1993) The case for a multi-disciplinary child and adolescent mental health community service. Discussion paper, avallable from author, c/o Tavistock Clinic, London.

KURTZ, Z. (1992) With Health in Mind. Mental health care for children and young people. London: Action for Sick Children.

LGHT, D. \& BAnEY, V. (1993) Pound foolish. Health Services Journal, 108, (11 February). 16-18.

RoYAl COUBGe of PSYCHITRISTS (1994) Newsletter of the Child and Adolescent Section. Summer.

SLADE, M. (1994) Needs assessment. British Journal of Psychiatry. 166, 293-296.
StzVEnS, A. \& GABBAY, J. (1991) Needs assessment needs assessment. Health Trends, 23, 20-23.

Vanstrazlen, M. \& CotrReu, D. (1994) Child and adolescent mental health services: purchasers knowledge and plans. British Medical Journal, 309. 259-261.

R. P. W. Fry, Senior Registrar, Department of Psychological Medicine, The Hospitals for Sick Children, Great Ormond Street, London WC1N 3JH.

\section{Trust and control}

\section{Lary Culliford}

Where human relationships are concerned, issues of trust and control go together. Where professional relationships are concerned. these issues require special attention.

I will let you take control, give me orders, make directions and offer advice - if I trust you.

I will let you take control, give me orders, make directions and offer advice to the extent that I trust you. The level of my trust may fluctuate. You are wise to pay attention to this. When I trust you absolutely, you may do with me as you will.

It may be best when there is mutual trust. Control may then be shared. Sometimes I will make decisions affecting us both. Sometimes you will make such decisions. Sometimes we will make them together.

When I want to take control, to make decisions and see them carried through. I will endeavour to gain and retain your confidence, hence your respect and esteem. (Only later perhaps, when trust is assured, will I hope for and anticipate your affection.)
I will endeavour to be trustworthy. This involves keeping you informed and telling you no lies. I will hope for the same honesty and trustworthiness from you.

I recognise how difficult it is to provide these conditions. I will strive towards patience, tolerance, understanding and forglveness in our dealings. I will hope for the same patience. tolerance, understanding and forgiveness from you.

Where human failings arise, I will endeavour to put my trust in a just and benevolent universe. If I go about my business faithfully, may I confidently anticipate the rewards of my trust, faith and fidelity? On the deepest and most earnest reflection, I do not doubt this so far... and give thanks.

\section{Larry Culliford, Consultant Psychiatrist, Hove Community Mental Health Centre, Hove BN3 4AG}

